\title{
Redundancy and word perception during reading
}

\author{
DAVID ZOLA \\ University of Illinois at Urbana-Champaign, Champaign, Illinois
}

\begin{abstract}
The experimental investigation reported in this article deals with the process of extracting visual information during reading. Subjects read texts that manipulated the predictability of a target word through the choice of an immediately preceding word. Spelling errors were also introduced into some of the target words. A detailed examination was made of the subjects' eye-movement patterns. Several aspects of eye behavior were analyzed to determine if contextual constraint and misspelling influenced perception during reading. Subjects exhibited no differences in the frequency of fixating the target words in the high-constraint and low-constraint conditions. However, the fixation of the target words was shorter in the high-constraint condition. In addition, fixation durations and regression probabilities associated with misspelled words were also significantly inflated. The eye-movement patterns showed that minimal spelling errors often disrupted reading, even when the misspelled words were highly predictable. These results suggest that language constraint does expedite processing during reading; furthermore, they suggest that such facilitation does not necessarily occur through a reduction in the visual analysis of the text.
\end{abstract}

To understand how perception takes place in any particular task, two fundamental questions must be dealt with. First, it is necessary to determine what is serving as the stimulus information for perception. Second, it is necessary to identify the perceptual activities by which the extraction and use of this stimulus information yields its effects. The first of these questions is the most directly empirical in nature. If experimental research can specify the information that is "picked up" for a perceptual activity under precise conditions, then an understanding of the mental events of perception under those conditions can be addressed more profitably. Without sound evidence about the stimulus information extracted, further theorizing about perceptual activities is somewhat meaningless.

The purpose of this research was to determine whether contextual information influences what visual information is noticed and used during reading. At any given moment in time, when a person is engaged in the cognitive activity of reading, there are a great many sources of information that can be used to identify meaning. Such information might include the reader's linguistic awareness, the reader's background knowledge, the reader's understanding of the meaning of the text up to that given moment, and, of course, the visual characteristics of the segment of text the reader is currently considering.

The research reported here specifically addressed the

The research described in this paper was supported by Grant MH 32884 from the National Institute of Mental Health to George McConkie, and by National Institute of Education Contract HEW-NIE-C-400-76-0116 to the Center for the Study of Reading. The author wishes to thank George W. McConkie for his comments on earlier versions of the manuscript. Copies of this paper can be obtained from David Zola, Center for the Study of Reading, 51 Gerty Drive, Champaign, IL 61820. issue of linguistic redundancy's influence on the perception of words in reading. What effect does this structural variable have on the extraction of the information contained in printed texts? Does it influence how visual information is acquired and used? This question has motivated and continues to motivate much research activity.

There is a substantial body of research that shows that the structural constraints of language expedite the perception of language (Garner, 1962; Gibson, Pick, Osser, \& Hammond, 1962; Marslen-Wilson \& Welsh, 1978; Miller, Bruner, \& Postman, 1954; Reicher, 1969). The experiments that appear to be most directly relevant to the relationship between redundancy and visual perception in continuous reading show that a verbal context provided by a sentence frame improves the accuracy and speed with which a word is recognized (Morton, 1964; Pearson \& Studt, 1975; Perfetti \& Roth, 1981; Pillsbury, 1897; Pollack, 1964; Schuberth \& Eimas, 1977; Tulving \& Gold, 1963; Tulving, Mandler, \& Baumal, 1964; West \& Stanovich, 1978). For illustrative purposes, consider the seminal study by Tulving and Gold in which sentence fragments (e.g., THE SKIERS WERE BURIED ALIVE BY THE SUDDEN ...) provided the context for tachistoscopically presented final nouns (e.g., AVALANCHE). Visual duration thresholds for the correct identification of the nouns were lower (i.e., noun identification was $27 \mathrm{msec}$ faster) in the full-sentence context condition than in the no-context condition. The theoretical explanation most often proposed for this verbal context effect stresses an interaction of contextual and visual information. Perception is assumed to be facilitated by using available contextual information to reduce the degree to which the perceiver must depend on the visual detail information afforded by the printed array. 
Many theoretical approaches to the reading process suggest that language constraint reduces the amount of visual information from the text that the reader must notice to make the requisite discriminations and identifications (Goodman, 1967; Haber, 1978; Smith, 1971). That is to say, the presence of a context reduces the number of visual cues necessary for the correct identification of words (Morton, 1964). While the reader is extracting information from a word, he or she already has the contextual information in mind. Therefore, efficiency is assumed to be gained by making use of the interword and intraword contextual information inherent in printed prose to circumvent some visual analysis. For example, consider the theoretical perspective offered by Smith, who regards readers as "predicting" their way through a text as they eliminate some alternatives on the basis of their knowledge of the redundancy of language, while acquiring just enough visual information to eliminate the remaining alternatives. Such a position argues for a strong and dominant role for usage of the nongraphemic, contextual information contained in the structure of the prose being read. The use of contextual information to reduce the amount of visual information that must be extracted from text is the typically hypothesized mode of processing in skilled reading.

It is important to point out that the major source of evidence for this selectivity of visual detail perspective comes primarily from studies using impoverished stimulus information (e.g., Morton, 1964; Tulving \& Gold, 1963). These experiments typically involve stimuli that, by their nature, afford the perception of only partial visual information. The appropriateness of generalizing these results to reading is often questioned (Gibson \& Levin, 1975; Gough, 1975). Although many investigations of the role of context in the perception of words and their component letters have been conducted, there have been only a few studies involving subjects who were engaged in normal reading (Ehrlich \& Rayner, 1981; Eisenberg, 1981).

The occurrence of errors in oral reading and proofreaders' errors provides a further suggestion that certain visual information is not utilized in reading. When people read orally, they sometimes make errors, often inserting words that are not in the text, leaving out words, or replacing words with other words (Goodman, 1969). In most cases, these miscues are contextually appropriate to the text. It is also often quite difficult to recognize certain misspellings and misprints in text. Contemporary researchers using proofreading and letter-cancellation tasks (e.g., Smith \& Groat, 1979) have demonstrated that proof errors involve the variables of expectation, familiarity, phonology, and spatial location. One possible explanation for these types of errors is that during reading some visual information is not noticed and that this reading habit carries over into proofreading and letter-cancellation tasks.

The major objective of the current experiment was to provide a test of the hypothesis that a verbal context influences the perception of words during reading. Such a perspective would predict that readers extract less stimulus information from highly redundant words in text, and that readers are less likely to "look at" or fixate a word if the word's usage is certain or predictable. The eyemovement patterns of skilled readers were examined to ascertain if these speculations were indeed correct. It was assumed that if a highly predictable word was not fully analyzed visually, then this could be observed in two ways. First, there would be fewer fixations directly on the word; and second, if the word was misspelled, this error would be less likely to disrupt the reading.

\section{Subjects}

\section{METHOD}

Twenty undergraduate college students who were considered to be skilled readers ${ }^{1}$ were paid for their voluntary participation in this experiment. They each read a series of paragraphs while their eye movements were monitored and recorded by computer. All subjects were native speakers of English, had uncorrected vision, were free of visual abnormalities, and were experienced with the eye-movement monitoring procedures employed. Each subject individually participated in three experimental sessions.

\section{Equipment}

A computer-based laboratory system was used for displaying the text to be read and for monitoring and recording the eye-movement patterns of the subjects. This laboratory facility is centered amound a Digital Equipment Corporation (DEC) PDP-11/40 computer with a laboratory peripheral system and a DEC VT-11 graphics display system. The text was displayed one line at a time with upper- and lowercase characters produced by the VT-11's hardware character generator. Pressing a button called the next line of text onto the display, permitting subjects to read multiline passages without difficulty. The display was $48 \mathrm{~cm}$ from the subject's eyes, with three letter positions subtending $1^{\circ}$ of visual angle. Eye movements were monitored using a modified Biometrics Model SC limbus reflection eye-movement monitor (Young \& Sheena, 1975). The computer sampled the horizontal component of the eye position signal every millisecond. A more complete description of this system can be found in McConkie, Zola, Wolverton, and Burns (1978).

\section{Text Materials}

The text materials used consisted of 132 short paragraphs, 32 nonexperimental and 100 experimental, each consisting of a group of sentences that developed a single topic or idea. Each of these short prose segments was written to contain exactly five lines of text, with each of the first four lines being between 69 and 73 character positions in length. Each experimental paragraph possessed an embedded noun whose redundancy could be manipulated by selecting the word that was used as its preceding adjectival modifier. That is to say, the occurrence of the noun was more probable following one adjective than it was following another adjective. For example, the word botanical can make it highly probable that the next word in a paragraph about tourism in San Diego is gardens. However, when the word botanical is replaced by the word beautiful, the word gardens is much less predictable. Thus, by manipulating the word preceding it, a selected noun was made to have a differential level of constraint. Predictability data ${ }^{2}$ indicated that the high-redundancy phrases used in this study yielded substantially greater noun predictability than the low-redundancy phrases.

Included as criteria for selecting highly constraining adjective-noun phrases were the following: (1) The noun had to be either seven or eight letters in length, (2) the adjective had to be between six and nine letters in length, and (3) the adjective could not be a primary associate of the noun. The less contraining adjective that was identified for each target phrase in the experimental paragraphs also met several criteria: (1) It had to be semantically compatible with the noun, (2) it had to be less constraining on the noun than the original adjective, (3) it had to have the same number of letters as the more highly constraining adjective, and (4) its frequency of occurrence had to be equal to or greater than that of the more highly constraining adjective.

Two versions of each experimental paragraph were prepared, one containing the highly constraining adjective and one containing the other adjective. The two versions of each paragraph differed by only one word. Appendix 1 contains the two versions of one paragraph. 


\section{Degraded Spellings}

To assess the readers' sensitivity to the visual detail information of words that is noticed during reading, specific misspellings of the nouns were introduced into some paragraphs. Four categories of degraded spelling were selected. The intent was to create a series of progressively more gross deviations of the conventionally spelled word. These graduated alternatives were achieved by the substitution of letters according to a precise algorithm. ${ }^{3}$ The resulting misspelled letter strings were selectively substituted for the nouns in the target adjective-noun phrases.

\section{Design and Procedure}

This experiment employed a $2 \times 5$ within-subject factorial design. Specifically, there were two levels of noun redundancy afforded by the choice of the preceding adjectives and five levels of degraded spelling. Since the entire focus of this research was to study the perceptual process of reading in a representative environment (Brunswik, 1956), the task given to the subjects was simply to read the passages silently and be prepared to answer comprehension questions about them.

Each subject was seated in front of the display unit and was physically positioned for head stability. A bite bar and headrest helped to minimize movement. After a brief, initial calibration of the eye-position monitoring equipment, the experimental procedure was explained.

The subject was told that the text consisted of a series of five-line paragraphs, each dealing with a different topic, and that there were occasional errors in the text. It was further explained that the errors were unimportant, had no bearing on the task at hand, and could be ignored. This procedure was adopted after pilot sessions had shown that if subjects were not told that errors were in some texts, they quickly adopted a strategy of looking for errors. An initial group of 12 paragraphs was used to acquaint the subject with the task of reading with occasional spelling errors. Then, the experimental paragraphs were presented in groups of six (i.e., one warm-up and five experimental). After each group, the subjects were administered a set of five comprehension questions associated with the just-read paragraphs. Each subject read 10 paragraphs under each condition in a within-subject randomization design for a total of 100 experimental paragraphs.

\section{RESULTS}

The data that are presented involve three aspects of the eye-movement behavior of the subjects. (See Appendix 2 for a more detailed description of the structure of the data.) They are: (1) location of fixations (i.e., where in the text readers centered their eyes during pauses), (2) duration of specific fixations (i.e., the duration, in milliseconds, of the pauses at various locations), and (3) parameters of saccades (i.e., the direction and length of various eye movements).

\section{Frequency of Fixating the Target Locations}

Figure 1 presents the frequency distributions of fixations at each relative character position for the high- and lowconstraint conditions with no spelling degradations. The data for each position were selected for successive threeletter regions, and the total number of fixations in each region were plotted on a letter-by-letter basis. This technique affectively resulted in a smoothing of the curves. The segment of a sample line of text is printed on the horizontal axis to show the relationship of the relative character positions to the target adjective-noun phrase. These data patterns clearly show that the target noun was fixated just as frequently when the constraint was high as when it was low.

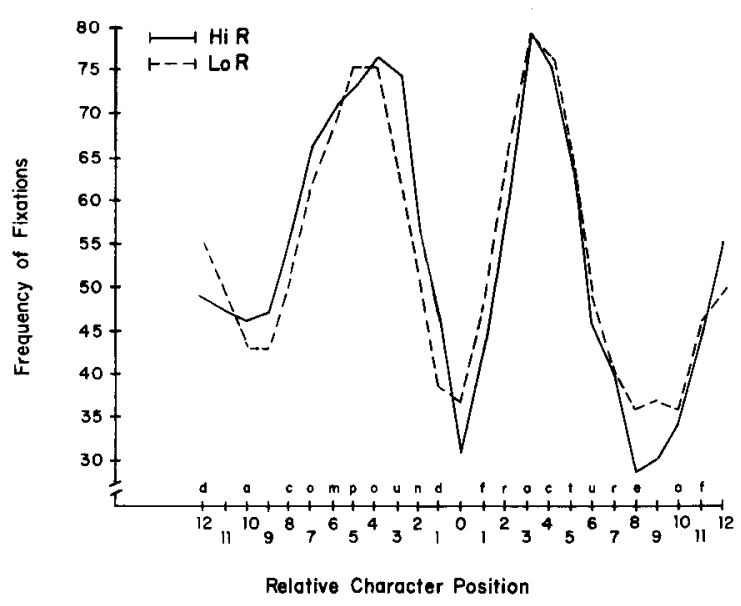

Figure 1. Number of fixations at each relative character position for the high-and low-constraint conditions with no spelling degradation. The segment of a sample line of text is printed on the horizontal axis to show the relationship of the relative character positions to the target adjective-noun phrase.

\section{Analysis of Fixation Durations}

For each subject, a median value was selected from all the initial fixations located on the central region of the critical words. ${ }^{4}$ The central region of a word simply refers to all the letters of a word, excluding the initial and final letters. Selecting the data on this basis, ensured that the durations used in the analysis resulted from actual fixations of the critical words. Each subject contributed one median fixation duration value for each of the 10 conditions. It is important to point out that the distributions in Figure 1 clearly showed that both the critical adjective and noun were directly fixated with high probability [i.e., subjects centered their eyes on the critical adjective location (CAL) and the critical noun location (CNL) over $94 \%$ of the time in all conditions]. Therefore, stable estimates of the time a subject spent in fixating either word location were available. These summary statistics were used as indices to examine the temporal effects of the experimental manipulations on the eye-movement patterns. ${ }^{5}$

Columns 3 and 5 of Table 1 present the means of medians for each of the experiment's conditions for the CAL and the $\mathrm{CNL}$ regions, respectively.

The analysis of the median durations on the CAL revealed no difference across all experimental conditions. In other words, the initial fixations on the adjective location exhibited no differences or perturbations in fixation durations in the region just before the CNL.

The analysis of fixations on the CNL revealed main effects for the redundancy factor $[F(1,190)=5.65, p<.02]$ and the degraded spelling factor $[\mathrm{F}(4,4)=96.67, \mathrm{p}<$ $.001]$, but the interaction of the two factors was not significant. Orthogonal comparisons demonstrated that each of the degraded spelling conditions differed significantly from its control condition $(p<.01)$. It appears that centering a word on the fovea ensures the "pickup" of visual 
Table1

Summary of Various Eye-Movement Dependent Variables

\begin{tabular}{|c|c|c|c|c|c|}
\hline \multicolumn{2}{|c|}{$\begin{array}{c}\text { Experimental } \\
\text { Condition }\end{array}$} & \multicolumn{4}{|c|}{$\begin{array}{l}\text { Fixating on the Central Region } \\
\text { of the Target Words }\end{array}$} \\
\hline Redundancy Level & $\begin{array}{c}\begin{array}{c}\text { Degraded Spelling } \\
\text { Level }\end{array} \\
\end{array}$ & $\begin{array}{c}\text { Fixation Duration } \\
\text { on CAL } \\
\text { (msec) }\end{array}$ & $\begin{array}{l}\text { Saccade Length } \\
\text { to CNL } \\
\text { (cp) }\end{array}$ & $\begin{array}{c}\text { Fixation Duration } \\
\text { to CNL } \\
\text { (msec) }\end{array}$ & $\begin{array}{l}\text { Saccade Leaving } \\
\text { the CNL } \\
\text { (cp) }\end{array}$ \\
\hline High & $\begin{array}{c}\text { Control } \\
\text { DS1 } \\
\text { DS2 } \\
\text { DS3 } \\
\text { DS4 }\end{array}$ & $\begin{array}{l}236 \\
236 \\
242 \\
243 \\
226\end{array}$ & $\begin{array}{l}8.2 \\
8.3 \\
9.0 \\
7.9 \\
6.4^{*}\end{array}$ & $\begin{array}{l}221^{* *} \\
248^{*} \\
246^{*} \\
275^{*} \\
310^{*}\end{array}$ & $\begin{array}{c}10.0 \\
9.1 \\
9.7 \\
8.6^{*} \\
7.3^{*}\end{array}$ \\
\hline Low & $\begin{array}{c}\text { Control } \\
\text { DS1 } \\
\text { DS2 } \\
\text { DS3 } \\
\text { DS4 }\end{array}$ & $\begin{array}{l}238 \\
235 \\
282 \\
242 \\
245\end{array}$ & $\begin{array}{l}8.7 \\
8.4 \\
7.9 \\
7.5 \\
5.7 *\end{array}$ & $\begin{array}{l}237 * * \\
266^{*} \\
275^{*} \\
305^{*} \\
328^{*}\end{array}$ & $\begin{array}{l}9.2 \\
9.5 \\
8.6 \\
8.2^{*} \\
7.1^{*}\end{array}$ \\
\hline
\end{tabular}

Note $-D S=$ degraded spelling; $C A L=$ critical adjective location; $C N L=$ critical noun location; $c p=$ the length of movement in number of letter positions. *The difference between experimental and control condition achieved statistical significance. **The difference between highand low-redundancy control conditions achieved statistical significance.

detail information from letters, even in highly redundant text regions. Even the minimal spelling degradation produced an inflated fixation duration on the CNL, suggesting that small deviations in spelling pattern were noticed when the erroneous information was foveally fixated (see Figure 2). Moreover, the perception of a word can be expedited by its preceding contextual environment as evidenced in the significant 16 -msec difference $(p<.05)$ between the high- and low-redundancy conditions (see both control conditions in Column 5 of Table 1).

\section{Analysis of Saccades}

Is there any evidence in the eye-movement records for differences or perturbations in the distance the eyes moved within the region of the CNL? In other words, did the experimental manipulations affect the lengths of specific saccades? The distance that the eyes traversed in moving to and from individual fixations on the CNL provides a way

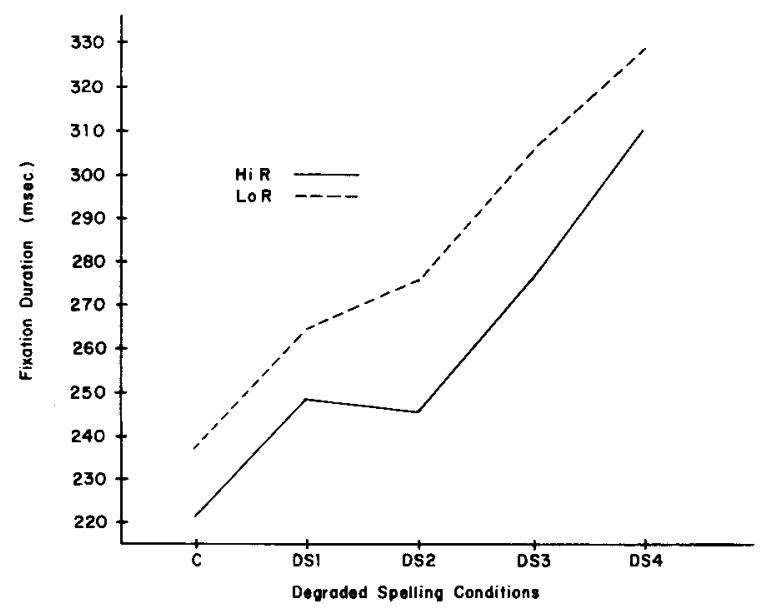

Figure 2. Effects of the experimental variables on the duration of fixations located in the central region of the critical noun location (CNL). of examining the influence of the experimental manipulations on another major characteristic of eye-movement patterns.

Saccade lengths. The analysis of the median saccadic lengths for forward movements resulting in fixations on the central region of the CNL (i.e., excluding fixations on the initial and final letters) revealed a significant main effect for the degraded spelling factor $[F(4,4)=9.42, p$ $<.03$ ]. The difference among condition means was attributable to the DS4 conditions, which manifested a significant foreshortening of forward movements when the word to which the eyes were being sent was grossly misspelled (see Table 1, column 4). Neither the redundancy factor $[F(1,190)=1.23]$ nor the interaction of the two factors $[F(4,190)=1.07]$ revealed effects.

The analysis of median saccadic lengths for forward movements after fixations on the central region of the CNL also revealed only a significant main effect for the degraded spelling factor $[F(4,4)=11.56, p<.02]$. Again, neither the main effect for the redundancy factor $[F(1,190)=1.52]$ nor the interaction $[F(4,190)=.62]$ achieved significance. The contrasts among group means for the degraded spelling factor revealed a significant effect for the DS4 conditions $[F(1,4)=35.94, p<.01]$ and for the DS3 conditions $[\mathrm{F}(1,4)=8.75, \mathrm{p}<.05]$ (see column 6 of Table 1).

Probability of regression. An inspection of the directionality of the eye movements in the region of the target nouns revealed that the proportion of fixations falling on the CNL that were immediately preceded by a regression significantly increased as a function of experimental condition. Statistical analyses were carried out using the arcsine transformation (Winer, 1971) of probability of regression as the dependent variable. Main effects for the redundancy factor $[\mathrm{F}(1,3)=57.08, \mathrm{p}<.005]$ and the degraded spelling factor $[F(3,3)=101, p<.002]$ were found. The interaction between the two factors was not significant. Figure 3 presents a graph of this proportional data as a function of four levels of spelling degradation 


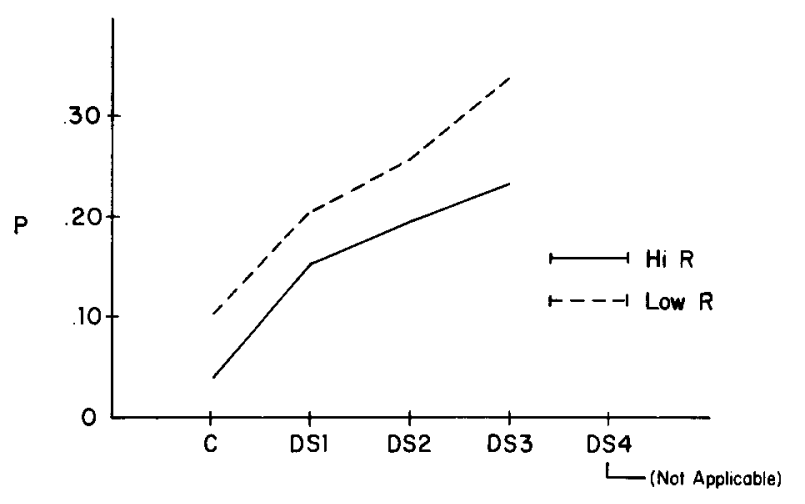

Degraded Spelling Conditions

Figure 3. Effects of experimental variables on the probability of regressing to the critical noun location (CNL). The most degraded spelling condition (DS4) resulted in almost a unity of proportional regressions, and is therefore not appropriate for presentation.

and two levels of redundancy. Frequency of regression involving the $\mathrm{CNL}$ was significantly greater for both of the minimal error conditions than it was for the respective control conditions $(\mathrm{p}<.05)$. In the high-redundancy control condition, the proportion was $4 \%$, whereas in the highredundancy DS1-condition, the proportion was $16 \%$. This analysis adds further support to the claim that even the minimal spelling error had some effect on the eyemovement behavior of some of the subjects.

\section{Summary}

The interword structure of the target phrases had no effect on where the subjects centered their eyes (i.e., the location of fixations), but did have an effect on how long individual pauses (i.e., fixation durations) were at the specific locations corresponding to fixation of the target nouns. The trends of each of the dependent variables involving the $\mathrm{CNL}$ are remarkably similar. In no analysis did the two experimental factors interact. In all analyses, the mean fixation time for the low-redundancy condition was greater than the mean fixation time for the corresponding high-redundancy condition. In all analyses, the levels of degraded spelling manifested a commensurate increase in fixation frequency and duration. The analysis of saccadic lengths showed perturbations of eye-movement pattern only with the more gross spelling degradations, and not with the redundancy factor. Moreover, an analysis of regressive movements also revealed effects of the experimental manipulations.

\section{DISCUSSION}

The data patterns revealed by this study are informative about several of the fundamental perceptual issues of reading. First, the data provided evidence that interword redundancy facilitates the extraction of information from text. The presence of a highly constraining verbal context makes a difference in the time a word is fixated, thus presumably reflecting a processing time difference.
In the control conditions, high contextual constraint reduced fixation time by $16 \mathrm{msec}$ when compared with the lower constraint condition, a finding similar to that of Ehrlich and Rayner (1981). This difference between the high- and low-redundancy control conditions seems to be somewhat smaller than the differences found in word recognition studies in which context was manipulated. The more pronounced effect reported in those studies might be attributable to a confounding from repeated presentation of the same word, or to a guessing strategy adopted by subjects when presented with degraded stimuli in a word identification task. Neither of these factors is involved in normal reading, in which the stimulus is rich in veridical information and its presentation to the retina is controlled by the reader and not the experimenter.

Thus, during reading, greater predictability of a word facilitates its processing, although the effect is not large.

Second, the data further suggest that this observed facilitation does not necessarily result from circumventing the extraction of certain aspects of the visual detail that is afforded by the printed text. There was no evidence that erroneous letters in a word had less effect when that word was highly predictable than when the predictability was much lower. Readers apparently notice small distinctions among letters within the region of text falling on the fovea, even from words that are almost completely predictable from the preceding context. From an information reduction point of view, these distinctions were certainly not necessary to identify the words, given the high degree of constraint used in this study. However, the data patterns from the degraded spelling conditions suggest that skilled readers notice specific letter information, down to small distinctions among letters. This finding argues that skilled reading does not involve a minimal use of visual information to simply add to available contextual information, or to test hypotheses generated from that information (Goodman, 1967; Haber, 1978; Smith, 1971). Instead, skilled readers are responding sensitively to small distinctions in the English language letter set from words that are almost completely predictable from the context.

However, it is still possible to explain the observed lack of interaction between redundancy and spelling degradation, while retaining the classical idea that context diminishes reliance on individual letters in reading. Such a position would suggest that under weak verbal context, spelling errors would interfere with processing, while under strong context, processing capacity would remain for spelling-error checking. If some of the subjects, some of the time, lengthened their fixations as the result of actively dealing with the degraded critical letter string, rather than attempting to ignore the error as instructed, then the fixation duration data were artificially influenced by their noticing the error. In other words, some of the subjects, some of the time, noticed the errors, whereas some of the subjects, some of the time, may not have noticed the errors as such.

An attempt was made to check the plausibility of this idea by examining the frequency distributions of fixation durations in the degraded spelling conditions. If these dis- 
tributions were simply more skewed towards longer durations, then the observed effects were probably due to some subjects' periodically noticing an error and making long fixations. However, this pattern was not found. Instead, the control condition in the high-redundancy category exhibited a greater positive skew than that observed in all the degraded spelling conditions.

Additional research is necessary to more vigorously test this classical hypothesis, using other eye-movement parameters sensitive to error detection (e.g., fixation durations prior to regressions to the degraded string).

Erhlich and Rayner (1981) presented some evidence suggesting that readers are more likely to misread more highly constrained words and argued that visual information is sometimes not used. Their explanation is compatible with the above findings in that the misreadings occurred primarily when the word was not directly fixated. Ehrlich and Rayner suggest that words can be identified from peripheral regions with less than full visual detail being available. In the present study, the critical words were longer than those used by Ehrlich and Rayner (i.e., seven and eight letters compared to five letters), resulting in their seldom going unfixated, and only data from directly fixated words were used in the analyses. Results from both studies, then, argue that when a word is directly fixated, high contextual constraint does not reduce the degree of its visual analysis. But, when a word is not directly fixated, and hence occupies a more peripheral location, it is more likely to be correctly identified if it is more highly constrained. Contextual constraint does not reduce the use of available visual information, but does expedite identification when some visual information is not readily available.

Third, the present study also provides data about the control of eye movements in reading. The results do not support the hypothesis that readers fixate only informationally rich areas of text (Hochberg, 1970). Degree of contextual constraint had no effect on the likelihood of fixating the critical nouns. This result agrees with Ehrlich and Rayner's (1981) second study, although they did find a difference in their first study. The reason for this discrepancy remains to be investigated. However, it should be noted that there was less experimental control over the characteristics of the context in their first study, which may explain the difference.

Spelling degradations, on the other hand, did shorten the length of the saccade coming to the critical noun. Thus, although the semantic characteristics of the critical word, when it lay to the right of the fovea, had no influence on saccade length, the orthographic characteristics of the word did. This result is compatible with the findings of O'Regan $(1979,1980)$. Lengths of saccades are influenced at least by word length patterns (McConkie \& Zola, 1984; O'Regan, 1979) and orthographic characteristics of near peripheral vision, but not necessarily by semantic characteristics, with the possible exception of high-frequency function words such as the word the (O'Regan, 1979).

Saccades following fixations of the more degraded letter strings were also significantly shortened. The process- ing involved in dealing with degraded words appears to inhibit the normal forward movement of the eyes. The foreshortening of saccades may be attributable to demands on the attentional system imposed by the degraded stimuli.

The results from the present study support two other observations from the literature. Readers show a strong tendency to fixate toward the centers of words (O'Regan, 1981; Rayner, 1979), and the time spent fixating words during reading reflects the characteristics of those words, either orthographic or semantic (Just \& Carpenter, 1980).

In conclusion, the results of this and other studies suggest that skilled readers have learned to extract visual information from text in a fast and efficient way that must involve the abstraction of relevant relational structure. Word perception in reading is an active search for relevant information strategically designed for task utility (Gibson, 1974). The full visual information afforded by the printed words of a text appears to be responded to by a system that is designed to extract useful information necessary for identification and differentiation. The subjects' detection of a minimal spelling error in a highly redundant word suggests that even in constrained regions of text, most of the visual information is noticed.

\section{REFERENCES}

BRUNSwik, E. (1956). Perception and the representative design of psychological experiments. Berkeley: University of California Press.

CLARK, H. H. (1973). The language-as-fixed-effect fallacy: A critique of language statistics in psychological research. Journal of Verbal Language and Verbal Behavior, 12, 335-359.

Davis, F. B., \& Davis, C. F. (1957). Davis reading test. New York: Psychological Corp.

EhrLich, S., \& RAYNer, K. (1981). Contextual effects on word perception and eye movements during reading. Journal of Verbal Learning and Verbal Behavior, 20, 641-655.

EISENBERG, P. M. (1981). Word expectancies in reading: The effect of text-constraints on error detection and eye movements during real-time reading. Unpublished doctoral dissertation, University of Minnesota.

GARNER, W. R. (1962). Uncertainty and structure as psychological concepts. New York: Wiley.

GiBson, E. J. (1974). Trends in perceptual development: Implications for the reading process. In A. D. Pick (Ed.), Minnesota symposia on child psychology (Vol. 8). Minneapolis: University of Minnesota Press.

Gibson, E. J., \& Levin, H. (1975). The psychology of reading. Cambridge, MA: M.I.T. Press.

Gibson, E. J., Pick, A. D., Osser, H., \& Hammond, M. (1962). The role of grapheme-phoneme correspondence in the perception of words. American Journal of Psychology, 75, 554-570.

Goodman, K. S. (1967). Reading: A psycholinguistic guessing game Journal of the Reading Specialists, 4, 126-135.

Goodman, K. S. (1969). Analysis of oral reading miscues: Applied psycholinguistics. Reading Research Quarterly, 5, 9-30.

Gough, P. B. (1975). The structure of the language. In D. D. Duane \& M. B. Rawson (Eds.), Reading, perception and language. Baltimore, MD: York Press.

HABER, R. N. (1978). Visual perception. Annual Review of Psychology, 29, 31-59.

HoCHBERG, J. (1970). Components of literacy: Speculations and exploratory research. In H. Levin \& J. P. Williams (Eds.), Basic studies on reading. New York: Basic Books.

Just, M. A., \& CARPENTER, P. A. (1980). A theory of reading: From eye fixations to comprehension. Psychological Review, 4, 329-354.

KIRK, R. E. (1968). Experimental design: Procedures for the behavioral sciences. Monterey, CA: Brooks/Cole. 
Marslen-Wilson, W. D., \& Welsh, A. (1978). Processing interactions and lexical access during word recognition in continuous speech. Cognitive Psychology, 10, 29-63.

MCCONKIE, G. W., \& ZoLA, D. (1984). Eye movement control during reading: The effect of word units. In W. Prinz \& A. F. Sanders (Eds.), Cognition and motor processes. New York: Springer.

McConkIE, G. W., Zola, D., Wolverton, G. S., \& BURNS, D. D. (1978). Eye movement contingent display control in studying reading. Behavior Research Methods \& Instrumentation, 10, 154-166.

Miller, G. A., Bruner, J. S., \& Postman, L. (1954). Familiarity of letter sequences and tachistoscopic identification. Journal of General Psychology, 50, 129-139.

MORTON, J. (1964). The effects of context on the visual duration threshold for words. British Journal of Psychology, 55, 165-180.

O'REgaN, J. K. (1979). Saccade size control in reading: Evidence for the linguistic control hypothesis. Perception \& Psychophysics, 25, 501-509.

O'REGAN, K. (1980). The control of saccade size and fixation duration in reading: The limits of linguistic control. Perception \& Psychophysics, 28, 112-117.

O'REGAN, K. (1981). The "convenient viewing position" hypothesis. In D. F. Fisher, R. A. Monty, \& J. W. Senders (Eds.), Eye movements: Cognition and visual perception. Hillsdale, NJ: Erlbaum.

Pearson, P. D., \& STUdT, A. (1975). Effects of word frequency and contextual richness on children's word identification abilities. Journal of Educational Psychology, 67, 89-95.

Perfetti, C. A., \& Roth, S. (1981). Some of the interactive processes in reading and their role in reading skill. In C. A. Perfetti \& A. M. Lesgold (Eds.), Interactive processes in reading. Hillsdale, $\mathrm{NJ}$ : Erlbaum.

Pillsbury, W. B. (1897). A study in apperception. American Journal of Psychology, 8, 315-393.

PoLLACK, I. (1964). Interaction of two sources of verbal context in word identification. Language and Speech, 7, 1-12.

RAYNER, K. (1979). Eye guidance in reading: Fixation locations within words. Perception, 8, 21-30.

REICHER, G. M. (1969). Perceptual recognition as a function of meaningfulness of stimulus material. Journal of Experimental Psychology, 81, 275-280.

SchuberTh, R. E., \& Eimas, P. D. (1977). Effects of context on the classification of words and nonwords. Journal of Experimental Psychology: Human Perception and Performance, 3, 27-36.

SMITH, F. (1971). Understanding reading: A psycholinguistic analysis of reading and learning to read. New York: Holt, Rinehart \& Winston.

SMITH, P. T., \& GroAT, A. (1979). Spelling patterns, letter cancellation and the processing of text. In P. A. Kolers, M. E. Wrolstad, \& H. Bouma (Eds.), Processing visible language (Vol. 1). New York: Plenum Press.

Tulving, E., \& Gold, C. (1963). Stimulus information and contextual information as determinants of tachistoscopic recognition of words. Journal of Experimental Psychology, 66, 319-327.

Tulving, E., MandleR, G., \& Baumal, R. (1964). Interaction of two sources of information in tachistoscopic word recognition. Canadian Joumal of Psychology, 18, 62-71.

WEST, R. F., \& StANOviCh, K. E. (1978). Automatic contextual facilitation in readers of three ages. Child Development, 49, 717-727.

WINER, B. J. (1971). Statistical principles in experimental design (2nd ed.). New York: McGraw-Hill.

Young, L. R., \& SHEENA, D. (1975). Survey of eye movement recording methods. Behavior Research Methods \& Instrumentation, 7, 394-429.

ZoLA, D., \& Wolverton, G. S. (1983). Discriminability of lower case letters: A similarity matrix. Unpublished manuscript.

\section{NOTES}

1. Each subject was administered the Davis Reading Test (Davis \& Davis, 1957). This standardized testing procedure was used to assess the reading ability of the subjects. The average level of comprehension score $($ mean $=84.1, \mathrm{SD}=6.11$ ) corresponded to the 86th percentile rank for adults, and the average speed of comprehension score (mean
$=87.2, \mathrm{SD}=4.83$ ) corresponded to the 93rd percentile rank. Selfreported S.A.T. scores (mean verbal score $=601$, $\mathrm{SD}=59.12$; mean quantitative score $=665, \mathrm{SD}=63.12$ ) provided additional evidence that the group was adept at reading.

2. The assessment of the predictability of the target nouns within the respective experimental paragraphs was obtained in a procedure in which 150 subjects were asked to provide completions to 100 paragraphic fragments that included the wording of the paragraphs up to the target nouns. On the average, the target nouns for the selected texts were given as responses over $82 \%$ (mean $=82.69, \mathrm{SD}=12.52$ ) of the time in the more constraining verbal environment, and less than $8 \%$ (mean $=7.95$, $\mathrm{SD}=9.50$ ) in the less constraining instance. Without going into further detail about the paragraph norming procedure, suffice it to say that the high-redundancy category yielded substantially greater noun predictability than did the low-redundancy category.

3. Figure 4 presents an exemplary composite of the five ways in which the noun gardens was spelled in this experiment. The minimal spelling degradation (referred to as Condition DS1) was achieved by a single letter substitution. The fourth letter in each noun (e.g., the letter $d$ in the word gardens) was changed to its most similar letter. The selection of the letter that was most visually similar to the original letter was based on a similarity matrix of all 26 lowercase letters obtained from an analysis of the same-different judgments of 24 subjects (Zola \& Wolverton, 1983). In the next, more gross type of spelling degradation (referred to as Condition DS2), the fourth letter of the original noun was changed to its most dissimilar letter within the same letter set. The notion of letter set refers to the division of the alphabet into ascenders, descenders, and all other letters. The third type of spelling degradation (referred to as Condition DS3) was achieved by substituting alternative letters for the fourth and fifth letters in each noun. This manipulation had the effect of changing the words' external shape or envelope. The fourth letter was again changed to its most similar letter, and the fifth letter was changed to a randomly chosen letter from another set. The most gross degradation of the original noun (referred to as Condition DS4) was constructed by substituting for the fourth letter the most dissimilar letter within the set, and by changing the first and last letters to randomly selected letters from sets other than the original letters.

4. Both indigenous monitoring equipment limitations and minor subject head movement introduced inaccuracies into the calculation of exact eye-position information. Therefore, precision in determining the exact letter being fixated was restricted to a range of plus or minus one letter position. In other words, the calculation from the eye-movement records of the exact letter upon which a fixation is centered often involves some error. It is also true that the distributions of fixation durations are markedly skewed. Several long fixation durations "pulled" the distributions in the positive direction, greatly influencing the mean as the measure of central tendency. For these two reasons, the construction of the de-

Conditions Letter String

Control

DS 1

DS2

DS 3

DS4 gardens

garbens

garfens

garbhns

darfenj
Figure 4. Examples of the various types of degraded spellings (DSn) used in this experiment. The misspelled letter strings were substituted for the nouns in the critical phrases. 
pendent variables for each subject involved the selection of a median value obtained from a three-letter position region. This statistical "filtering" technique yielded stable estimates of the dependent variables under consideration.

5. Throughout these analyses, the redundancy variable was treated as a random factor (Clark, 1973), and the degraded spelling factor was treated as a fixed factor. When the analysis procedures revealed significant main effects for the degraded spelling factor, a set of four independent orthogonal comparisons was calculated to test for significant differences between control and experimental group means. Occasionally, the main results suggested interesting additional, a posteriori theoretical questions. Therefore, several post hoc comparisons (Kirk, 1968) were made.

\title{
APPENDIX 1
}

\section{Sample Paragraphs}

\section{High-Redundancy Version}

\author{
The movie industry recently published a study that revealed a surprising \\ fact. Since movie theaters must have buttered popcorn to serve to their \\ patrons who wish to purchase it, the movie industry hired a sociologist \\ to find out how many people eat popcorn. His study showed that one out \\ of every four moviegoers buys a container of buttered popcorn.
}

\section{Low-Redundancy Version}

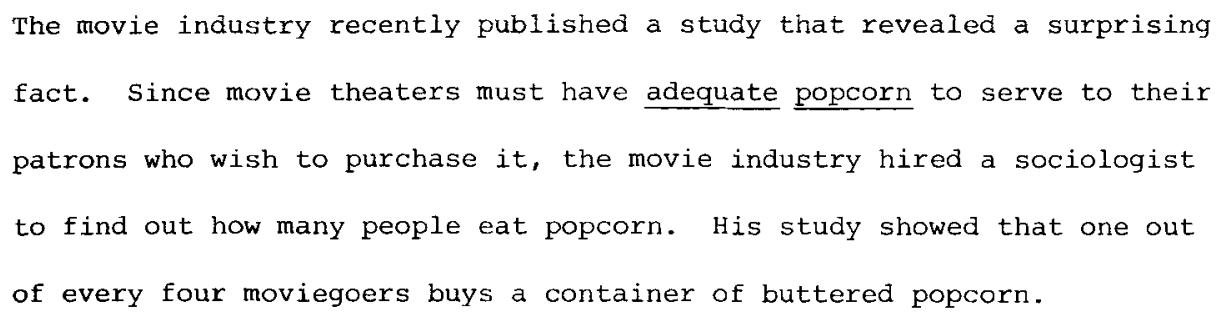

\section{APPENDIX 2}

In this study, the raw data consisted of 1-msec samples of the location of the eyes. These samples were recorded continuously during the entire reading of each passage. Eye position was measured on a scale in which an eye movement of $13^{\circ}$ of visual angle (i.e., the width of one letter position in the current experimental setup) corresponded to a change of about 40 values. A saccade was defined based on the velocity of the movement and on changes in movement trends. Transitions in four successive data samples of 10 values were taken as indicating saccadic movement.

Figure 5 presents a graph of some raw data, about $1 \mathrm{sec}$ worth, showing the location of saccades and fixations. In this figure, time is represented on the horizontal axis with each vertical line marking off $100 \mathrm{msec}$. Eye position is represented on the vertical axis with each horizontal line marking off a distance equivalent to an eye movement of about five letter positions. In the data curve, a flat line represents a period when the eyes are at rest, or in a fixation. When the curve begins to climb upward, as it does at the point marked with the letter $\mathrm{A}$, the eyes are beginning to move to the right. At the point marked with the letter B, the eyes have come to rest at a new location. That is to say, a new fixation has begun. This pause lasted $255 \mathrm{msec}$. It ended with the beginning of the next forward saccade that began at the point marked with the letter $C$.

A fixation was defined as the temporal duration between successive saccades. Its location was taken to be the position of the eyes halfway through the fixation interval. A simple linear in-

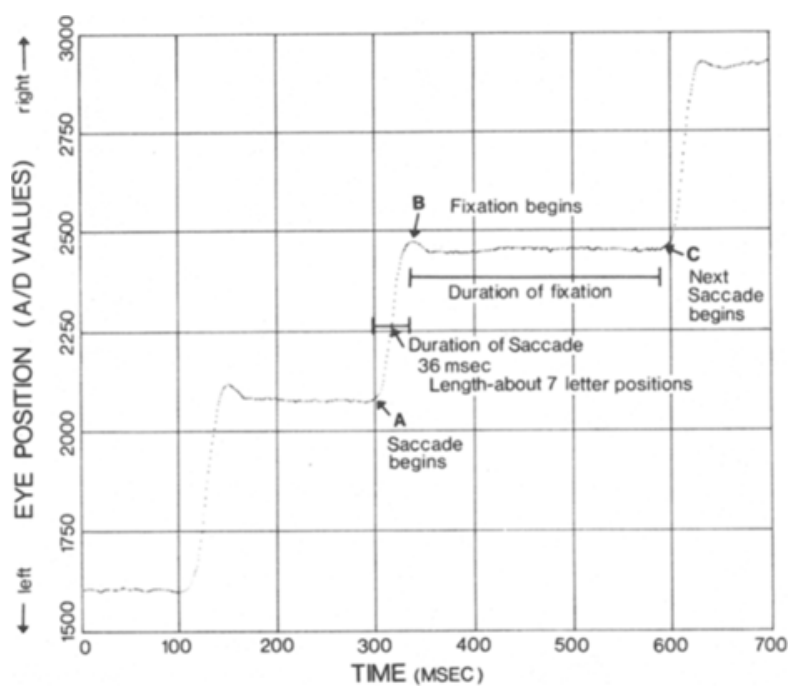

Figure 5. Data from a typical eye-movement record.

terpolation model based on a passage-specific calibration pattern was used to convert the fixation location value into character position information. Saccade size was defined as the distance between the location of successive fixations. 